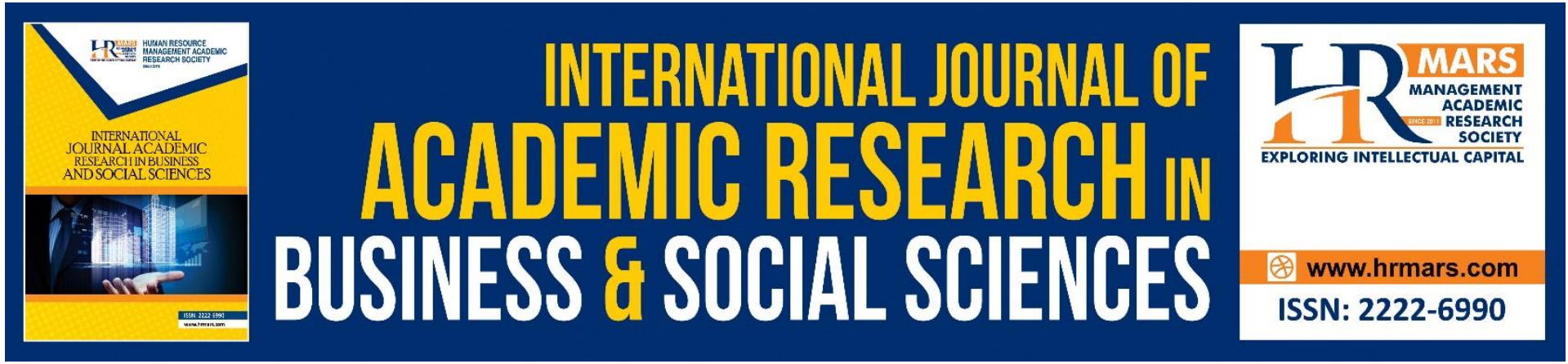

\title{
Examining the Moderating Effect of Geopolitical Environment on Crisis Management and Strategic Planning
}

Mohammed Waleed Mudalal

To Link this Article: http://dx.doi.org/10.6007/IJARBSS/v11-i9/10898

DOI:10.6007/IJARBSS/v11-i9/10898

Received: 05 July 2021, Revised: 28 July 2021, Accepted: 20 August 2021

Published Online: 10 September 2021

In-Text Citation: (Mudalal, 2021)

To Cite this Article: Mudalal, M. W. (2021). Examining the Moderating Effect of Geopolitical Environment on Crisis Management and Strategic Planning. International Journal of Academic Research in Business and Social Sciences, 11(9), 1025-1041.

Copyright: (c) 2021 The Author(s)

Published by Human Resource Management Academic Research Society (www.hrmars.com)

This article is published under the Creative Commons Attribution (CC BY 4.0) license. Anyone may reproduce, distribute, translate and create derivative works of this article (for both commercial and non-commercial purposes), subject to full attribution to the original publication and authors. The full terms of this license may be seen at: http://creativecommons.org/licences/by/4.0/legalcode

Vol. 11, No. 9, 2021, Pg. 1025 - 1041

http://hrmars.com/index.php/pages/detail/IJARBSS

JOURNAL HOMEPAGE

Full Terms \& Conditions of access and use can be found at http://hrmars.com/index.php/pages/detail/publication-ethics 


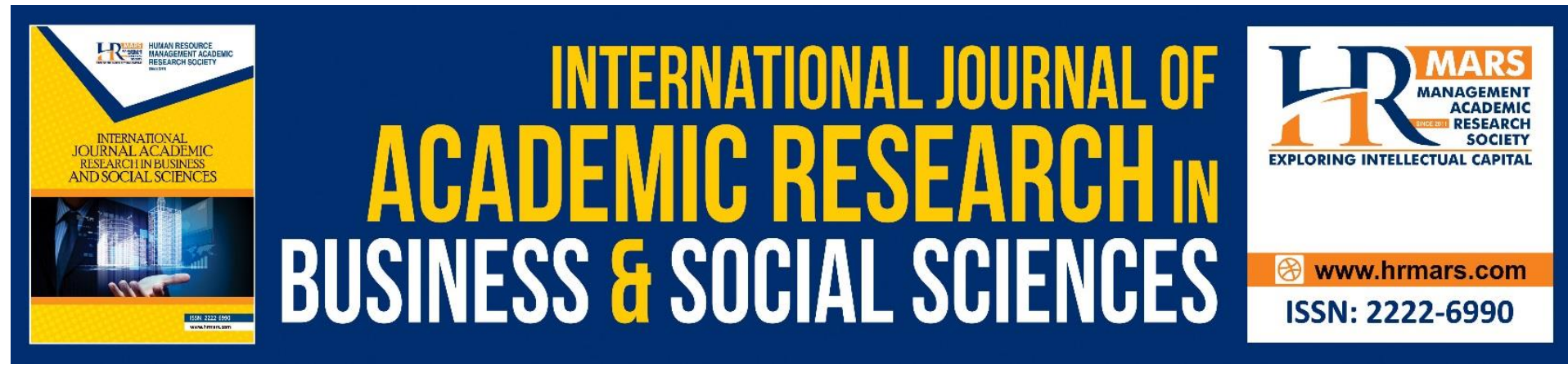

\title{
Examining the Moderating Effect of Geopolitical Environment on Crisis Management and Strategic Planning
}

\author{
Mohammed Waleed Mudalal \\ Azman Hashim International Business School, Universiti Teknologi Malaysia, 81310, Skudai, \\ Johor, Malaysia \\ Email: mohwaleed1984@gmail.com
}

\begin{abstract}
This study aims to examine the moderating effect of geopolitical environment on the relationship between crisis management and strategic planning in the service sector firms. Thus, examining the geopolitical environment variable will give a comprehensive perception to understand the crises environment and could strategically deal with these crises that considered as challenges to the service sector. A total of 120 questionnaires were collected from respondents who were chosen by the quota sampling technique. The results revealed that the geopolitical environment variable fully moderates the relationship between crisis management and strategic planning. The findings of this study can have significant implications for the service sector of Palestine. The study findings have several theoretical, practical, and managerial implications in the fields of crisis management, strategic planning and geopolitical environment. Consequently, this study suggested that it is advisable for service sector firms to invest in crisis management and encourage several strategic processes for providing firms with a defensive capability in order to prevent crisis developments or diminish their impacts.
\end{abstract}

Keywords: Geopolitical Environment, Crisis Management, Strategic Planning, Service Sector Firms.

\section{Introduction}

Most developing countries suffer from numerous economic, political, and administrative problems. This is particularly the case for countries who are facing poverty and a lack of resources, among which are the poorest countries in the world. Their firms are weak and defective, and their leaders are restricted by bureaucratic steps, personal interests, and different priorities. Some of these countries, which are surrounded by corruption and conflicts, are usually badly managed. In fact, those who work in the service sector, which is an important component of any country's economy and it makes a direct and significant contribution to GDP and job creation, are responsible for the success or failure of the country (Cali, 2008).

Each firm faces obstacles when trying to provide services to the public, where restrictions can occur due to political stability, lack of money, institutional capacity, or any other shortage. 
Accordingly, the instability in firms is considered as a very critical factor to their progress and works. For this reason, the concept of geopolitical environment has appeared strongly in today's firms particularly in conflict areas such as Palestine. Geopolitical environment plays a critical role in effecting those firms in a negative way.

Evidence shows that geopolitical environment plays a significant role in firms as an external effective factor that provokes managers to recognize first the necessity to develop the skills in order to handle any threat and challenge that will inevitably arise, and make it a priority to be ready to handle such a crisis, through careful and thorough preparation (Andrianopoulos, 2015).

Managing crises must still be well planned (Coombs, 2014). With crisis management, firms can be better prepared to handle unexpected events that may cause serious damage. Managing crises and responding appropriately to them will make the firm improve its abilities to survive and thrive (Pal et al., 2014; Vargo and Seville, 2011; Lockwood and SPHR, 2005). Hence, Vargo and Seville (2011) believed that crisis management focuses on coping with threats, while strategic planning focuses on revealing opportunities. The use of strategic planning in the time of crisis will significantly benefit the firm by having advantages to operate and to have resilience in dealing with uncertainties (Pal et al., 2014; Pal, 2013). Therefore, to be resilient, firms will need to use strategic planning intensively in turbulent and changing situations in order to survive and thrive, to have leaders able to inspire people with a sense of hope, to have an organizational society that overvalues well-organized planning while developing innovation and improving the performance, to plan and make decisions carefully and finally to have teams capable to recognize different models of crisis (Vargo and Seville, 2011; Ismail et al., 2011).

This study is significant in the business environment due to the limited number of studies of strategic planning and crisis management in unstable environment. Most of the empirical research studies, particularly in developing Arab countries, are concerned principally with the tools and techniques of strategic planning (Aldehayyat et al., 2011; Aldehayyat and Anchor, 2008; Al-Ghamdi, 2005). However, a few studies about strategic planning in times of crisis have been conducted to come out with real resolutions in order to treat any crisis that could impact the firm. Strategic planning as a strategy for crisis, provides a system to think strategically through several scenarios that could develop the best strategic response (Nickols, 2016; Gunther et al., 2005). Furthermore, planning in managing crises in firms can reduce the damages that caused by crises (Eldakak, 2014).

Firms clearly have a competitive advantage and readiness when they execute systematic planning processes (Vargo and Seville, 2011; Al-Ghamdi, 2005). Although firms are concerned with strategic planning in order to achieve advantages for business outcomes, and face crises, there is an obvious shortage of research in strategic planning at Palestinian firms in particular during the geopolitical situations (Awashra, 2013).

\section{Literature Review}

Geopolitical environment variable is very significant variable in this study to be underlined. Therefore, this study is expected to come out with positive practical findings that can achieve the overall goals of the firm particularly during the time of crises. This research also uses two theories (Dynamic Capabilities Theory and Open Systems Theory) as a theoretical base for this study. 


\section{Theoretical Perspectives}

Different theories have attempted to explain strategic planning processes in firms. Literature refers to the better management as a function of strategic planning undertaken by firms. The two theories of this study are the Dynamic Capabilities Theory (Teece et al., 1997) and the Open Systems Theory (Ansoff, 2007).

Both theories facilitate an understanding of the situation of crisis management into the strategic planning process within the turbulent system in addition to the moderation of geopolitical environment on the relationship between crisis management and strategic planning. The dynamic capabilities theory focuses on firm competitiveness in changing environments. Teece et al (1997) stated that 'dynamic' refers to a rapidly changing environment while 'capabilities' include internal and external organizational skills, competencies and learning methods.

In this context, Teece et al (1997) used the term "dynamic capability" to refer to a firm's capability order to renew abilities and skills over time in order to achieve similarity with a changing environment by joining in and reforming internal and external organizational skills, resources, and functional abilities in ways that strategically fit the requirements of change. In their seminal contribution, Teece and his colleagues argued that dynamic capabilities theory empowers firms to incorporate, build, and reconfigure their resources and competencies and therefore, keep good performance in the face of changing business environments. That is, this theory is the most suitable when talking about strategic processes in unstable environment. In a completely changing environment, such as the current situation, the concept of dynamic capabilities is assumed to be supportive in developing a framework for understanding why some firms succeed or fail to survive and thrive in the time of crises (Kitching et al., 2009). It has been claimed by authors such as (Bustinza et al., 2010; Eisenhardt and Martin, 2000) that dynamic capabilities enable firms to change their resources and strategies to the best and also in dealing with the external environment to integrate, build and shape internal and external competencies to more rapidly address the changing environment.

Contemporary strategic thinking considered dynamic capabilities to be the essential micro-foundations for managing environmental uncertainty and change processes (Teece et al., 1997). Specifically, the dynamic capabilities empower firms to create, deploy, and protect their intangible assets that support superior long-run business performance. The microfoundations of dynamic capabilities are comprised of the distinct skills, processes, procedures, organizational structures, decision rules, and disciplines embedded in three core capabilities: (1) Sensing environmental changes to identify threats and opportunities, (2) converting resources into viable business opportunities, and (3) reconfiguring the firm by recombining resources in structures that can use opportunities under the new market and technological conditions (Teece, 2007).

Hence, sensing is the ability to obtain early signals about things to happen and seizing is the ability to mentally hold these signals and use them to capture new opportunities for fast advantage. Thus, it is argued that firms with strong dynamic capabilities are highly risk-taking because they are adapted to the surrounding business system and can respond to crises through new innovations (Teece, 2007). According to Baretto (2010), the dynamic capabilities theory has received growing attention in the field of strategic planning research, focusing on the strategy implementation that is provided by a certain resource constellation over time to fit changing business crises and to manage these crises strategically in order to maintain performance in the face of changing business conditions. In short, this theory is employed in 
firms to integrate crisis management and strategic planning in order to build and reconfigure internal and external challenges for dealing with rapidly changing environments.

Similarly, this argument is in line with the open systems theory. Both theories are rooted in firm behavior and differ since every firm has its own learning to study these two theories. The open systems theory was first applied in firms by Katz and Kahn (1978). Based on their view, the firm depends on its environment by applying the open systems theory in order to ensure its sustainability. As they asserted, this theory makes people and their firms have an open relationship with the external environment particularly to ensure adaptation with instabilities such as economic and political situations. Open systems theory views and focuses on the relationships between the firms and the environment. This focus was reflected in firms' aptitude to adapt to changes in environmental situations (Mele et al., 2010).

Therefore, this study extended the open systems theory by setting a base for the external environment which affects the service sector firms in particular. As argued by (Preble, 1997), the open systems view included the external environment which is observed by crisis management and strategic planning researchers and proponents to use it broadly and critically in such situations. This theory has certainly played a big role in crisis management and strategic planning especially in the context of geopolitical environment. Firms operate as open systems by applying communications with the environment for survival and existence. Firms affect and are affected by the environment; thus, they operate as open systems within the environment. Kreitner (2007) argued that open systems approaches are applicable in achieving competitiveness as firms interact with environment through penetrable boundaries. Basically, the open systems theory made substantial contributions to the evolution and the operation of firms.

Accordingly, this approach must be viable because any firm must be able to reserve its viability and stability, creating its own internal environment that is able to respond effectively to external effects at any time. This adaptive and proactive behavior should be based on this theory in order to develop strong and sustainable performance (Mele et al., 2010). Managers should become familiar with the concept of systems and the way of thinking. They have to plan structural changes to guarantee the survival of the firm existence, continually formulating new interpretations of the business scenarios in order to find an adequate placing, applying, changing and redefining the organizational structure (Mele et al., 2010). In today's unstable environment, open systems theory is applicable and meaningful in achieving competitiveness (Namada, 2013). Therefore, any firm must be concentrating on any effect from the external environment and must constantly adapt to it (Voiculet et al., 2010).

Eventually, the firms affect and are affected by the environment, so they operate as open systems within the environment. The open systems theory importantly supported the framework of this study as a base for service sector firms to deal with the external environment particularly in the time of crises. Generally speaking, the research filled the theoretical gap by examining the moderating effect of geopolitical environment on the relationship between crisis management and strategic planning as a first study in Palestine.

\section{Crisis Management and Strategic Planning}

Literature has indicated that one of the prime attributes of development in local firms today is the role of managers including executive, planners, consultants and so on (Vargo and Seville, 2011). Crisis management in this context is seen as a significant factor for improving the service sector firms by studying the influence of crisis management on crisis planning. Prior studies found that one of the main factors as a dynamic capability that affect the process 
of strategic planning is Crisis Management, which has a positive effect on any strategic process. Therefore, crisis management can significantly influence the strategic planning processes in firms according the similarities between both concepts (Karam, 2018; Vargo \& Seville, 2011; Pollard and Hotho, 2006; Evans and Elphick, 2005). Furthermore, (Priporas and Poimenidis, 2008) found that crisis management is influential and powerful especially in the strategic process of the service sector firms.

Al-Qubaisi and Hussein (2013) stated that there is a high degree of consideration of crisis management and strategic planning in firms where the performance of the two concepts is recommended for further studies. In addition, Al Shobaki et al., (2016) revealed that general findings of their study showed that there is a relation between crisis management and strategic planning based on literature. However, this relation is still in need of more development and expansion. Further, there are shortcomings in the way that firms manage the crises before and after they occur. Crisis management is only practiced during the crisis; therefore, it must be involved in the strategic planning processes to endure and prosper. Results and other findings supported this view that is crisis management is a substantial variable for strengthening and improving strategic process in the service sector firms. So, the developed hypothesis for this relationship is:

H1 There is a significant positive influence of Crisis Management on Strategic Planning.

Crisis management in firms is exclusively linked with particular dimensions of strategic planning (Aljuhmani and Emeagwali, 2017) where the performance of managers may enhance the understanding of the influence of crisis management over the strategic planning processes in firms and in the service sector in particular. Studies showed that there is a direct relation of crisis management on strategic planning. For instance, Crandall et al., (2010) stated that firms in environment characterized by low uncertainty should be managed differently from those marked by high uncertainty. When uncertainty is low, strategic planning is high and establishes managerial procedures by management which can be implemented to increase certainty, improve efficiency, and lessen the impact of crisis events.

\section{Geopolitical Environment, Crisis Management and Strategic Planning}

Crisis management has become gradually ineffective in light of a rapidly changing geopolitical environment characterized by an overall retreat of power globally, a weakening commitment to focus on progress, and increasingly uncontrolled financial troubles (Simón, 2012). Furthermore, (Teixeira and Dias, 2013) stated that the geopolitical environment has a notable and a positive influence on both crisis management and strategic planning. Hence, in this study, geopolitical environment is used as a moderator to significantly affect the relationship between crisis management and strategic planning. On the other hand, with the rapid change and continuous development today, particularly in developing countries, many scholars and researchers such as (Priporas and Poimenidis, 2008; Crawford and Bryce, 2003) have reported the necessity to focus on managers with different managerial levels to solve problems and to deal with crises.

Managers therefore are being developed to handle this speedy change, as well as encounter and manage crisis in each level of a firm. On the basis of the above discussion, it is hypothesized: 
H2 Geopolitical environment moderates the relationship between crisis management and strategic planning.

Previous studies concluded about role played by the geopolitical environment as a moderator and also with individual effects on strategy. As claimed by (Wamalwa et al., 2014), environmental demand is a key moderating factor on effective strategy and crisis management such as the geopolitical factor to be studied. Similarly, the moderating effects by geopolitical environment have also been found by (Kasim and Dzakiria, 2016) who arguing that understanding the geopolitical context of a business is essential and urgent need. Furthermore, Kegode (2005) argued that, in order to be vital, economically valuable and profitable in the market environment, firms have to adapt to external environment. Kegode's study also stated that with taking into consideration the effect of environmental forces, as a moderator, it is impossible to formulate a strategy. Therefore, the choice of strategy alone cannot guarantee effectiveness in the process particularly in times of crisis, without considering the role of geopolitical factor in that relationship and its moderating effect (Mbithi et al., 2017).

The study framework consists of two major parts as shown in figure 1 below. From left to right, the first part shows crisis management that is proposed to be examined on strategic planning process and to develop the strategic planning symptoms among managers and staff members. The second part shows the geopolitical environment as a moderator variable affects the relationship between crisis management and strategic planning. Therefore, the outcomes of this framework are intended to show the ability of the firm managers to think strategically during a crisis is a key factor in a firm's long-term survival. This model demonstrates a critical instrument through which the crisis management perspective enhances strategic processes in firms by applying the appropriate approaches to these concepts and in turn, achieves a higher level of good performance and produces a robust strategic planning process.

In the same context, this study suggests that approaches to geopolitical environment are important moderators that could play a significant role in crisis management and strategic planning. Explicitly, based on earlier arguments, crisis management is expected to increase the effectiveness of the strategic planning processes. (Preble, 1997) stated that a strategic planning process that does not have crisis management is not SP process at all and it is subject to failure especially in turbulent environment. Similarly, as claimed by (Vargo and Seville, 2011), by combining crisis management with strategic planning, firms can effectively deal with crises to survive and prosper. (Karam, 2018) also expressed the same opinion, which is that crisis management and strategic planning can promote the effectiveness of the firm performance in coping with crises especially in the service sector. This study argues that geopolitical environment is a useful way to understand how crisis management positively affects the strategic planning process. In the context of service sector, promoting strategic planning means that managers should adjust and respond differently to each crisis situation and according to the excessive pressure that they face in making fast decisions, they must be responsible for any action taken in managing crises within firms, and they professionally work as individuals and as a team. 


\section{Figure $1 \quad$ Conceptual framework}

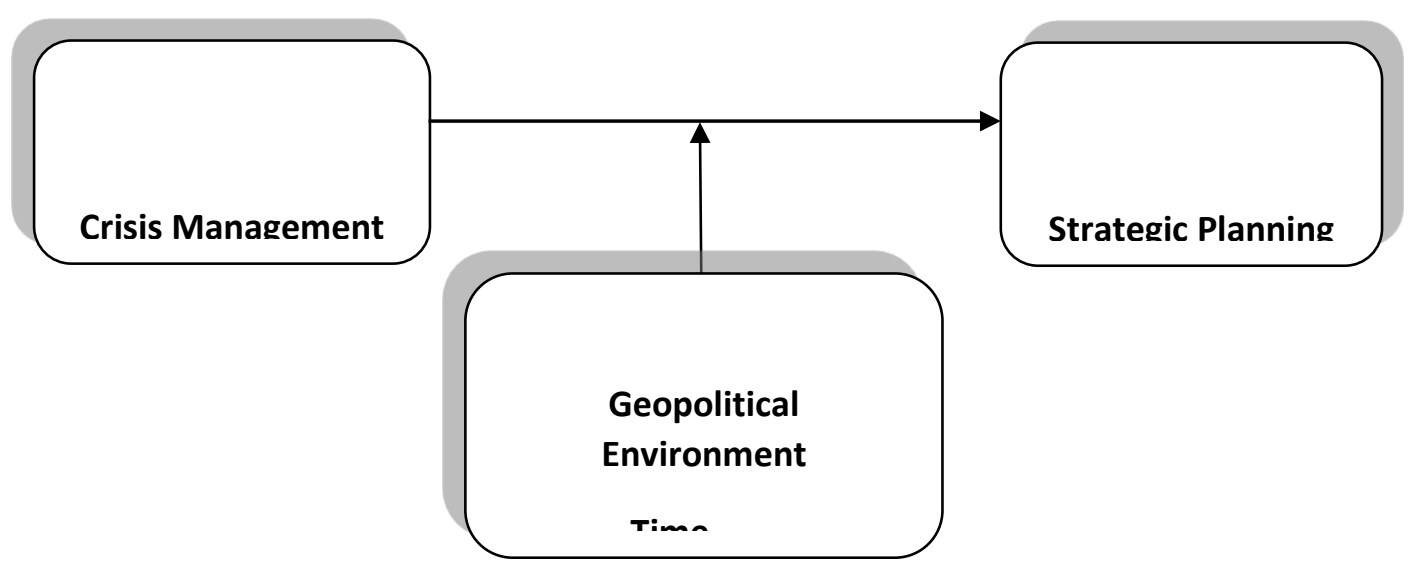

\section{Methodology}

Research context

The study was conducted with managers at the service sector firms in Palestine as the study respondents. A total of 120 questionnaires were distributed particularly in one of the biggest service sector firms in southern governorates of Palestine which is located in Gaza called Gaza Electricity Distribution Company (GEDCO). The study covered a total of 109 respondents out of 120 managers working at GEDCO in Gaza Strip, yielding a response rate of \%95. The quantitative survey portrayed the managers' actions and beliefs by asking managers to respond to problems regarding what they think about, and how they implement their plans. Managers were classified in the company into three types: top-level managers, middle-level managers and low-level managers. First, top-level managers are responsible for controlling and observing the entire company. Second, middle-level managers are responsible for executing organizational plans which comply with the company's policies and those managers act in the middle position between top-level management and low-level management. Third, low-level managers or line managers, focus on controlling and directing the strategic plans that provided by top management. They were considered as role models for employees in the company whereas their involvement in the strategy process gives it more credibility and reliability in an effective way.

\section{Population and Sampling}

The population of the study as identified was 120 full time managers working in different units of the company. Representativeness of the sampling reflected the level of 1032eneralization for the other firms in the service sector (Zechmeister et. al., 2006). Therefore, this study included all managers in the managerial levels of the company as respondents. 
Table 1 Sample Size

\begin{tabular}{ll}
\hline Categories & Sample size \\
\hline Planning Department & 37 \\
\hline Financial Department & 25 \\
\hline IT Department & 18 \\
\hline Marketing \& Logistics Department & 16 \\
\hline Technical Department & 12 \\
\hline Customer Service Department & 12 \\
\hline Total & $\mathbf{1 2 0}$ \\
\hline
\end{tabular}

Source: (GEDCO, 2018)

For this study, sample size was determined and used as a basis to analyze the data collected. The sample was determined for quantitative survey questionnaire data collection. The selection of sample size for quantitative data collection was done through quota sample technique (Taherdoost, 2016).

Measures

Table 2 shows the sources for the measures of the constructs used in the study. Thoroughly, the numerical scale of Likert five-point was applied in this study. All the questions were adapted from the existing questionnaires that already have been tested for reliability and validity. Further, all scales in this questionnaire were also arbitrated by experts in UTM Malaysia and top Palestinian universities.

Table 2 Constructs and measures

\begin{tabular}{llc}
\hline Sources & Constructs & Cronbach's alpha \\
& $(\boldsymbol{\alpha})$ & 0.931 \\
\hline As-Saber et al, (2001) & Geopolitical environment & 0.885 \\
Boltz (1999) & Crisis management & 0.884 \\
Phillips (1996) & Strategic planning & \\
\hline
\end{tabular}

\section{Data analysis}

The original data was gathered on hard copies of questionnaires disseminated among sample population and then it was being converted into digital form using SPSS (22.0 version). Path analysis approach was adopted for the study using SmartPLS version 3.0 which was considered as a popular software program with a graphical user interface for variance-based structural equation modelling (SEM) using the partial least squares (PLS) method. The software can be used in empirical research to analyze the collected data and test hypothesized relationships among variables. More importantly, process macro 2.16.3 was used in this study for evaluating the moderation effects (Objective Knowledge) path analysis and bootstrapping method.

\section{Results and Discussions}

\section{Pilot Test}

Table 3 shows the breakdown of respondents by gender, education and years of experience for the pilot test. These variables use nominal and categorical type of data respectively. The analysis is reported in frequency and percentage form. The demographic information of respondents retained in the study. The specific demographic information sought in the study included the respondents' gender, education, years of experience and position obtained. The 
descriptive results revealed that total numbers of male and female participated in the questionnaires were 86 males and 23 females respectively which showed the majority of respondents were male, by $78.9 \%$ of the total.

In terms of educational qualification showed that the bachelor degree holders constituted the majority of the respondents ( $n=74 ; 67.9 \%)$. The second largest group comprised persons with Diploma ( $n=23 ; 21.1 \%)$. Master's degree holders made up a total of $11 \%$, $(n=12)$.

Table 3 Profile of respondents for pilot test

\begin{tabular}{llll}
\hline Profile of Respondents & Frequency & \% \\
\hline Gender & Male & 86 & 78.9 \\
& Female & 23 & 21.1 \\
\hline \multirow{2}{*}{ Education } & Diploma level & 23 & 21.1 \\
& Bachelor's degree level & 74 & 67.9 \\
& Master's degree level & 12 & 11.0 \\
& Diploma level & 23 & 21.1 \\
& Bachelor's degree level & 74 & 67.9 \\
\hline \multirow{2}{*}{ Experience } & 1- less than 3 & 18 & 16.5 \\
& 3- less than 5 & 5 & 4.6 \\
& 5- less than 7 & 6 & 5.5 \\
& 7-less than10 & 27 & 24.8 \\
& Above 10 & 53 & 48.6 \\
\hline
\end{tabular}

Reliability Statistics

Table 4 Reliability Statistics

\begin{tabular}{cc}
\hline Reliability Statistics & Sample size \\
\hline Cronbach's Alpha & No. of Items \\
\hline .870 & 47
\end{tabular}

Reliability analysis is the procedure used to determine the internal consistency of measures. According to Hair et al. (2011) Cronbach's alpha above 0.6 for exploratory study is considered reliable. In the research, the range of Cronbach's alpha is between 0.811 and 0.884 . Thus, all measures in the study are reliable. Following internal consistency achieved from the pilot test, the researchers proceeded with data collection. The subsequent sections describe the analysis on the sample.

Descriptive profile of sample

Table 5 shows the variables use nominal and categorical type of data respectively. The analysis is reported in frequency and percentage form. Descriptive profile of sample represented the results of descriptive statistics of the study latent variables. The results signified the item-wise values of arithmetic mean, their standard deviations, accompanying the Cronbach's $\alpha$ of respective constructs, analyzed through SPSS v. 22. 
Table 5 Descriptive Statistics

\begin{tabular}{lcccll}
\hline & Range & $\begin{array}{c}\text { Maximum } \\
\text { Variance }\end{array}$ & Mean & Std. Deviation & \\
\hline Position & 8.0 & 9.0 & 3.532 & 2.3475 & \\
Gender & 1.0 & 5.511 & & & .168 \\
Education & 2.0 & 2.0 & 1.211 & .4099 & .314 \\
Ex. Years & 4.0 & 3.0 & 1.899 & .5602 & \\
Valid N (list wise) & & 5.0 & 3.844 & 1.4856 & \\
& & 2.207 & & & \\
\hline
\end{tabular}

Respondents were asked to indicate their agreement or disagreement for each statement based on a five-point Likert scale, ranging from ( 1 = Strongly Agree to $5=$ Strongly Disagree). To enhance the power of the instrument, responses to questions in the questionnaire included the multiple choice, open-ended responses, and Likert-type scale (Sue and Ritter, 2012). The Likert-type scale for this study was also to provide adequate judgment without confusing participants or rising non-response rates (Sue and Ritter, 2012).

This part measured the geopolitical environment variable through its dimensions: time, place and demographic. Where the items in this scale were developed by As-Saber, et al., (2001) and used by different authors such as: (Biswal, 2016; Teixeira and Dias, 2013). This scale was consisted of five statements and was modified to be appropriate to the Palestinian geopolitical environment. The purpose of this part was to enable managers in the Palestinian service sector to evaluate how well they have the ability to work in the geopolitical situations and their effectiveness in dealing with crises. It was also designed to choose on the potentially changing perspectives that managers may have about their roles as individuals and how well they are working as a team.

Table 6 Profile of Likert-scale measures

\section{Geopolitical environment measures}

Mean

1. The company follows up the geopolitical events constantly.

2. The company attempts to get benefits of any geopolitical event and turns it into opportunity.

3. The company cares about time in dealing with the geopolitical issues professionally.

4. The company takes into consideration the spatial dimension in addressing any geopolitical issue in the future.

5. The company develops its relationships with the external bodies consistently. 


\section{Partial least square findings}

Partial least square technique was applied to detect relationships among constructs. Convergent validity is achieved if loadings of the measures to their respective constructs are at least 0.60 (Kline, 2010). The result in table 7 shows a significant positive relationship existed between Crisis Management and Strategic Planning $(\beta=0.862, t=5.070, p<0.01)$. Table 8 shows the range of loadings thus establishing convergent validity. The composite reliability (CR) of all constructs were above 0.6 and average variance extracted (AVE) were above 0.5 (Fornell and Larcker, 1981) thus further supporting convergent validity.

Table 7 Results of Hypotheses Testing for Direct Relationships

\begin{tabular}{|l|c|c|c|}
\hline \multicolumn{1}{c}{ Constructs } & Original Sample & T Statistics(|O/STDEV |) & P Value \\
\hline $\mathrm{CM}>\mathrm{SP}$ & 0.362 & 5.070 & 0.000 \\
\hline Note: ${ }^{* *} p<0.01$, (one-tail); $\mathrm{CM}=$ Crisis Management; SP= Strategic Planning. \\
\hline
\end{tabular}

Table 8 Loading, CR and AVE

\begin{tabular}{lllll}
\hline Construct & Item & Loading & CR & AVE \\
\hline Geopolitical environment & GE1 & 0.750 & 0.949 & 0.788 \\
& GE2 & 0.886 & & \\
& GE3 & 0.915 & & \\
& GE4 & 0.955 & & \\
& GE5 & 0.918 & & \\
\hline
\end{tabular}

\section{Analysis of Moderation Variable}

The moderation variable in this study was Geopolitical Environment. The moderation analyses were conducted using the product indicator approach in SMART-PLS. Table 9 shows the results of the moderation analysis, which indicated a significant interaction of crisis management and geopolitical environment on strategic planning $(\beta=-0.148 ; t=3.425 ; p<$ 0.01). This indicated that geopolitical environment boosted the association among crisis management and strategic planning. The bootstrap estimates for the moderation model for the $\mathrm{CM}^{*} \mathrm{GE}$ interaction on strategic planning estimated in PLS; with CM functioning as the predictor variable and geopolitical environment as a moderator.

Table 9 Result of Hypothesis Testing for DV and Moderator Relationship

\begin{tabular}{|l|c|c|c|}
\hline \multicolumn{1}{|c|}{ Constructs } & Original Sample & T Statistics(|O/STDEV|) & P Value \\
\hline $\mathrm{GE}->\mathrm{SP}$ & -0.148 & 3.425 & 0.000 \\
\hline Note: $* * * \mathrm{p}<0.01$, (one-tail); GE= Geopolitical Environment; SP= Strategic Planning. \\
\hline
\end{tabular}

The result in the above table showed a significant negative relationship existed between Geopolitical Environment and Strategic Planning $(\beta=-0.148, t=3.425, p<0.01)$. Basically, the aforementioned results indicated that all the hypothesized direct relationships were significant at less than $5 \%$ significance level $(p<0.05)$. The final results were presented in table 10 and figure 2 below.

Table $10 \quad$ Moderation Hypothesis

\begin{tabular}{|c|c|c|}
\hline No. & Statement & Result \\
\hline $\mathrm{H} 2$ & $\begin{array}{c}\text { Geopolitical environment moderates the relationship between crisis } \\
\text { management and strategic planning }\end{array}$ & Supported \\
\hline
\end{tabular}


Figure 2 PLS Bootstrapping Results for the Moderating Effects CM*GE on Strategic Planning.

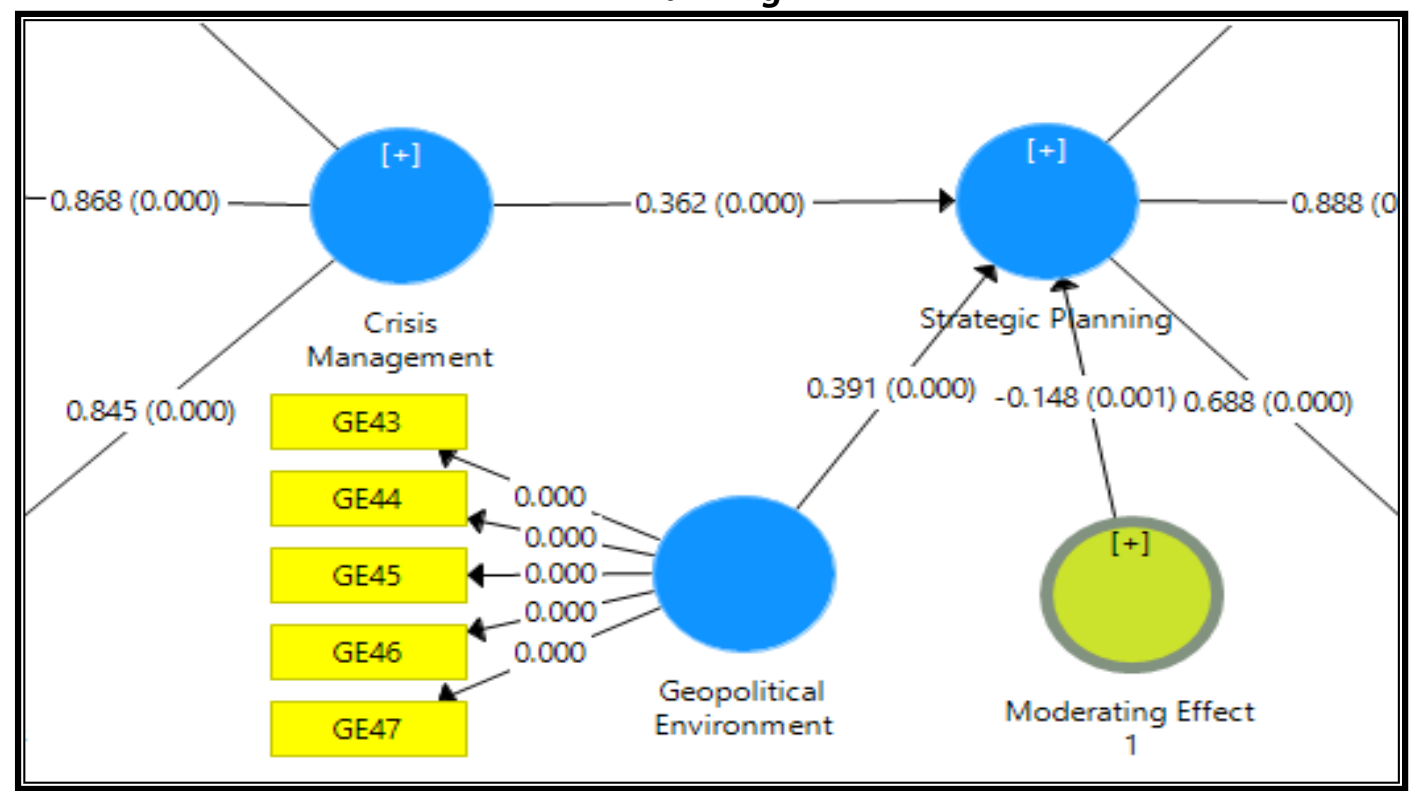

Aiken and West (2002) confirmed that the simple slope analysis that is shown in figure 3 revealed a significantly slope of geopolitical environment as the geopolitical environment (GE) dampens the positive relationship between crisis management (CM) and strategic planning (SP). The higher the Geopolitical Environment, the weaker the relationship between Crisis Management and Strategic Planning. When GE is low, CM increases and its influence gets stronger and Strategic Planning as well. In stable environment the crisis can be managed smoothly and leisurely as the time is fair enough to think strategically and find out solutions. On the other hand, when GE is high, CM decreases and gets weaker and its effect is powerless. Managing the crisis and planning for it, is very hard and tough in uncontrollable situations (instability).

Figure 3 Simple Slope Analysis for CM*GE on Strategic Planning

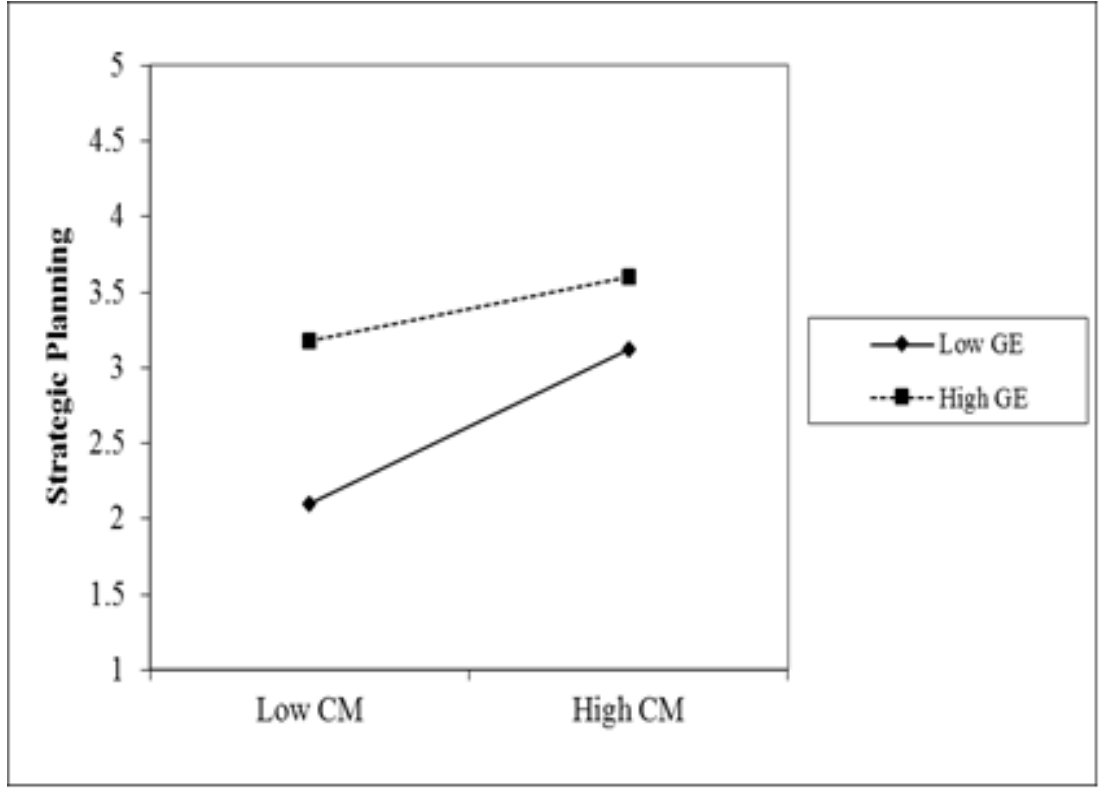




\begin{tabular}{|c|c|}
\hline Variable names: & \\
\hline $\begin{array}{c}\text { Name of independent } \\
\text { variable: }\end{array}$ & $\mathrm{CM}$ \\
\hline Name of moderator: & $\mathrm{GE}$ \\
\hline $\begin{array}{c}\text { Unstandardized Regression } \\
\text { Coefficients: }\end{array}$ & \\
\hline Independent variable: & 0.362 \\
\hline Moderator: & 0.391 \\
\hline Interaction: & -0.148 \\
\hline Intercept / Constant: & 3 \\
\hline
\end{tabular}

Table 11 Summary of Hypotheses Results

\begin{tabular}{l|l}
\hline \multicolumn{1}{c|}{ Hypotheses } & Findings \\
\hline H1 Crisis Management has a significant positive influence on Strategic & Supported \\
Planning. & \\
H2 Geopolitical Environment has a significant negative influence on & Supported \\
Strategic Planning. &
\end{tabular}

\section{Conclusion}

This study attempted to successfully fill the gap in the theoretical literature by examining the moderating effect of geopolitical environment on the relationship between crisis management and strategic planning among managers in the Palestinian service sector firms. The findings of this study revealed that the crisis management variable and the strategic planning variable have significant positive relationship. More importantly, these findings confirmed that practicing crisis management in all managerial levels, qualifies the foundation of geopolitical environment approaches which in turn resulted in promoting the strategic planning processes in firms. In other words, managers and leaders in the service sector have the responsibility to create an environment that adopts several perspectives and approaches in order to achieve better levels of strategic planning. Future research can examine how other variables may moderate the relationship between crisis management and strategic planning.

From a theoretical view, the study covered several aspects by recognizing the potential interests related to crisis management, strategic planning and geopolitical environment. It was significant to existing knowledge, since it was supported by the two distinct theories: the Dynamic Capabilities Theory (DCT), and the Open Systems Theory (OST). Moreover, the study was considered as one of the first studies in the field of geopolitical environment literature which developed and validated a theoretical framework for the relationship between crisis management and strategic planning. Hence, the findings confirmed that crisis management has a significant positive influence on strategic planning and its dimensions which also works more effectively in the situation of the geopolitical environment. The contextual contribution confirmed that the study extended a more comprehensive understanding of the level of strategic planning among managers in the service sector firms specifically in the geopolitical environment. The geopolitical environment played its role essentially as it underlined the relationship of crisis management and strategic planning and showed up their necessity in firms. In the same context, the study offered potential advantages to managers in order to 
practice crisis management for getting greater outcome success. Basically this study may serve managers to realize the important role of crisis management concerning approaches to strategic planning and geopolitical environment.

\section{References}

Aiken, L. S., \& West, S. G. (2002). Applied Multiple Regression/Correlation Analysis for the Behavioural Sciences. UK: Routledge Academic.

Al Shobaki, M. J., Amuna, Y. M. A., \& Naser, S. S. A. (2016). Strategic and Operational Planning As Approach for Crises Management: Field Study on UNRWA. International Journal of Information Technology and Electrical Engineering. 5 (6):43- 47.

Aldehayyat, J. S., Al Khattab, A. A., \& Anchor, J. R. (2011). The use of strategic planning tools and techniques by hotels in Jordan. Management Research Review, 34(4), 477-490.

Al-Ghamdi, S. (2005), "The use of strategic planning tools and techniques in Saudi Arabia: an empirical study", International Journal of Management, Vol. 22 No. 3, pp. 376-95.

Aljuhmani, H. Y., \& Emeagwali, O. L. (2017). The Roles of Strategic Planning in Organizational Crisis Management: The Case of Jordanian Banking Sector. International Review of Management and Marketing, 7(3).

Al-Qubaisi, S.A.K., Hussein, A.M. (2013). The role of strategic planning in the effectiveness of crisis management: Field research for the opinions of a sample of directors of the ministry of planning. The Journal of Administration and Economics, 94, 253-275.

Andrianopoulos, A. (2015). Essential Steps for Crisis Management and Crisis Containment. 126109 IB X3215.

Ansoff, I. H. (2007). Strategic Management. New York, Macmillan.

As-Saber, S. N., Dowling, P. J., \& Liesch, P. W. (2001). Geopolitics and its impacts on international business decisions: a framework for a geopolitical paradigm of international business. School of Management, University of Tasmania.

Awashra, R. (2013). NGO Strategic Planning in the Occupied Palestinian Territory: A Futile Exercise. Available at SSRN 2241323.

Baretto, J. (2010). Writing the ideal paper for JOM: A new editor's perspective, Journal of Operations Management, 20(1), 1-18.

Biswal, S. (2016). Geopolitics and its impact on Global business scenario: A Framework for Managing Growth \& Sustainable Development. Asian School of Business management, Bhubaneswar Odisha Vol 3, 1- 17 pages.

Bustinza, O. F., Molina, L. M., \& Arias-Aranda, D. (2010). Organizational learning and performance: Relationship between the dynamic and the operational capabilities of the firm. African Journal of Business Management,4(18), 4067.

Cali, M. (2008). The contribution of services to development and the role of trade liberalization and regulation. Overseas Dev't Institute.

Crandall, W., Parnell J.A. \& Spillan J. E. (2010). Crisis Management in the New Strategy Landscape, SAGE Publication, Inc. Pembroke. University of North Carolina. USA.

Crawford, P., \& Bryce, P. (2003). Project monitoring and evaluation: a method for enhancing the efficiency and effectiveness of aid project implementation. International journal of project management, 21(5), 363-373.

Eisenhardt, K. M., \& Martin, J. A. (2000). Dynamic capabilities: what are they?. Strategic management journal, 21(10-11), 1105-1121.

Eldakak, S. (2014). Leadership in Crises: The Ultimate Challenge. Advances in Economics and Business, 2(6), 232-237. 
Evans, N., \& Elphick, S. (2005). Models of crisis management: An evaluation of their value for strategic planning in the international travel industry. International Journal of Tourism Research, 7(3), 135-150.

Fornell, C. and Larcker, D. F. (1981). Evaluating Structural Equation Models with Unobservable Variables and Measurement Error. Journal of Marketing Research. 39-50.

Hair, J. F., Ringle, C. M., \& Sarstedt, M. (2011). PLS-SEM: Indeed, a silver bullet. Journal of Marketing theory and Practice, 19(2), 139-152.

Ismail, H. S., Poolton, J., \& Sharifi, H. (2011). The role of agile strategic capabilities in achieving resilience in manufacturing-based small companies. International Journal of Production Research, 49(18), 5469-5487.

Karam, M. G. (2018) The Impact of Strategic Planning on Crisis Management Styles in the 5Star Hotels. Journal of Hotel \& Business Management 7 (1), ISSN: 2169-0286.

Kasim, A., \& Dzakiria, H. (2016). Exploring the effects of macro-environment on the predisposition to adopt strategic orientation among small medium size hotel entrepreneurs. International Journal of Economics and Financial Issues, 6(7S).

Katz, D., \& Kahn, R.L. (1978). The social psychology of organizations (2nd ed.), New York: Wiley.

Kegode P. (2005), Economic Governance Reform in the Sugar Sub Sector Center for Governance and Development. Nairobi, Kenya.

Kitching, J., Blackburn, R., Smallbone, D., \& Dixon, S. (2009). Business strategies and performance during difficult economic conditions.

Kline, R. B. (2010). Promise and Pitfalls of Structural Equation Modeling in Gifted Research. In Thompson B., Subotnik R. E. (Eds.), Methodologies for Conducting Research on Giftedness (pp. 147-169).

Kreitner, R. (2007). Management. 10th Ed, Boston, Houghton Mifflin Company.

Lockwood, N. R., \& SPHR, G. (2005). Crisis management in today's business environment. SHRM Research Quarterly, 4, 1-9.

Mbithi, B., Muturi, W., \& Rambo, C. (2017). Macro environment moderating Effects on Strategy and Performance. 2(5), p, 197-209.

Mele, C., Pels, J., \& Polese, F. (2010). A brief review of systems theories and their managerial applications. Service Science, 2(1-2), 126-135.

Namada, J. M. (2013). Strategic planning systems, organizational learning, strategy implementation and performance of firms in export processing zones in Kenya (Doctoral dissertation, University of Nairobi).

Pal, R. (2013). Organizational resilience through crisis strategic planning. (Doctoral Dissertation). Tampereen teknillinen yliopisto - Tampere University of Technology Tampere.

Pal, R., Torstensson, H., \& Mattila, H. (2014). Antecedents of organizational resilience in economic crises - an empirical study of Swedish textile and clothing SMEs. International Journal of Production Economics, 147, 410-428.

Pollard, D., \& Hotho, S. (2006). Crises, scenarios and the strategic management process. Management Decision, 44(6), 721-736.

Preble, J. F. (1997). Integrating the crisis management perspective into the strategic management process. Journal of Management Studies, 34(5), 769-791. Press Publishing.

Priporas, C. V., \& Poimenidis, I. (2008). Services managers' awareness of crisis management: attitudes and preparation. Innovative Marketing, 4(3), 37-45. 
Simón, L. (2012). CSDP, strategy and crisis management: out of area or out of business?. The International Spectator, 47(3), 100-115.

Sue, V., \& Ritter, L. (2012). Conducting online surveys. (2nd Ed.). Los Angeles, California: Sage Publications.

Taherdoost, H. (2016). Sampling methods in research methodology; How to choose a sampling technique for research. International Journal of Academic Research in Management (IJARM), 5, No. 2, 2016, Page: 18-27.

Teece, D. J. (2007). Explicating dynamic capabilities: the nature and micro foundations of (sustainable) enterprise performance. Strategic management journal, 28(13), 13191350.

Teece, D. J., Pisano, G., \& Shuen, A. (1997). Dynamic capabilities and strategic management. Strategic management journal, 509-533.

Teixeira, A. A., \& Dias, M. (2013). The importance of geopolitics in firms' international location decisions: The Polish case. Communist and Post-Communist Studies, 46(1), 79-93.

Vargo, J. \& Seville, E. (2011) 'Crisis strategic planning for SMEs: finding the silver lining', International Journal of Production Research, Vol. 49, No. 18, pp.5619-5635.

Voiculet, A., Belu, N., Parpandel, D. E., \& Rizea, I. C. (2010). The impact of external environment on organizational development strategy. Munich Personal RePEc Archive MPRA Paper No. 26303. JEL L1, 01, P23.

Zechmeister, J. S., Zechmeister, E. B., and Shaughnessy, J. J. (2006). Essentials of Research Methods in Psychology. McGraw-Hill: Higher Education. 